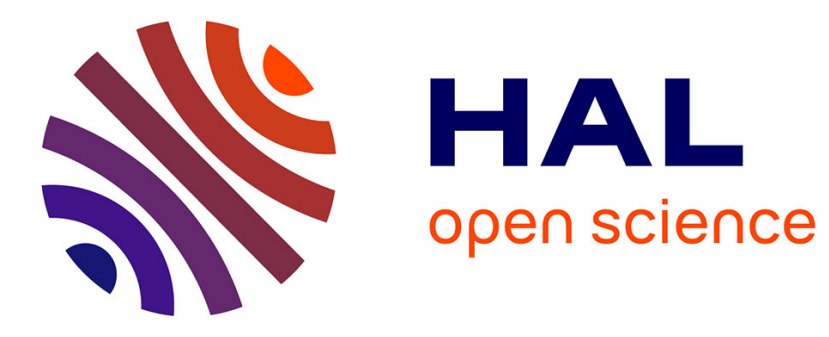

\title{
Pragmatics of Veridicity
}

Denis Vernant

\section{To cite this version:}

Denis Vernant. Pragmatics of Veridicity. Manuel Rebuschi; Martine Batt; Gerhard Heinzmann; Franck Lihoreau; Michel Musiol; Alain Trognon. Interdisciplinary Works in Logic, Epistemology, Psychology and Linguistics, 3, Springer, pp.229-244, 2014, Logic, Argumentation \& Reasoning, 9783-319-03044-9. 10.1007/978-3-319-03044-9_11. hal-02015506

\section{HAL Id: hal-02015506 https://hal.science/hal-02015506}

Submitted on 20 Mar 2019

HAL is a multi-disciplinary open access archive for the deposit and dissemination of scientific research documents, whether they are published or not. The documents may come from teaching and research institutions in France or abroad, or from public or private research centers.
L'archive ouverte pluridisciplinaire HAL, est destinée au dépôt et à la diffusion de documents scientifiques de niveau recherche, publiés ou non, émanant des établissements d'enseignement et de recherche français ou étrangers, des laboratoires publics ou privés. 


\title{
Pragmatics of Veridicity
}

\author{
Denis Vernant
}

\begin{abstract}
From the very beginning, Western philosophy was defined as the pursuit of truth. It approaches truth through the practice of logos, and more particularly via recourse to dialogue. Reviving the intuitions of the Megarians, I would like here to use the analytical tools of contemporary logic and pragmatics to propose a study of veridici$t y$, seen as the set of all attitudes expressed by a speaker about the truthfulness of what he/she is saying. ${ }^{1}$ In doing so, I will address only one stage of the multi-layered study of veridicity, ${ }^{2}$ which must be supplemented by the study of the dialogue games that establish validity or "material" truth $^{3}$ and in the end, the praxeological determinants proper of that veridicity. 4
\end{abstract}

\section{Veridictional acts}

Austin inaugurated his philosophy of ordinary language by denouncing the "descriptive fallacy" of philosophers and logicians who, in reducing all utterances to propositions, tackle only the descriptive, constative use of ordinary language. Thereafter, pragmatics began to emphasize the action-related or "performative" dimension of the social use of natural language. ${ }^{5}$ But the time has now come to look in return at veridictional acts in their systematicity, for they all bring to play the speaker's

Denis Vernant

Grenoble e-mail: Denis.Vernant@upmf-grenoble.fr

${ }^{1}$ I have defined veridicity, notably while distinguishing it from veracity, in [13, Chap. IV, 59-85].

${ }^{2}$ See my article [17].

3 See [21].

${ }^{4}$ See my book, [19, Chap. XI].

5 The acts in question are directives, commissives, and declaratives; see [13, Chap. III]. 
attitude about the truth of what he/she is saying. It is therefore important to start by characterizing these acts.

\subsection{Assertion}

As logicians have shown, assertion is, conceptually, the most prevalent type of veridictional act. ${ }^{6}$ Pragmatics defines it as the act by which a speaker makes a commitment about the truth of what he/she is saying to his/her addressee. This act manifests an explicit commitment, which can take on a variable degree of force depending on whether it is a simple assertion or a declaration made under oath, etc., or even on whether the assertion is metadiscursively doubled by the expression "I assert that...". 7

\subsection{Denial}

Assertion presupposes an act of acceptance of the propositional content of what is being said by the speaker. This act has a strictly pragmatic counterpart, which is the act of refusal of that same content via the expression of a denial. All too often confounded with simple negation, of which it often shares its surface linguistic form, it was first defined logically back in the 1930's by Łukasiewicz ${ }^{8}$ and psychoanalytically by Freud in his famous article on Verneinung [3]. I will characterize denial as the speech act by which a speaker expresses his/her refusal of what he/she is saying. ${ }^{9}$

\subsection{Consideration}

Assertion and its opposite, denial, are two acts by which the speaker expresses $a$ commitment, whether positive or negative, about what he/she is saying to the addressee. However, the speaker also has the possibility of not committing and thus

\footnotetext{
${ }^{6}$ See my article, [14, Chap. XIII, 267-288].

${ }^{7}$ On the pragmatic role of what I call expositives, see [15]. I will come back later to the iteration of assertions; see Section 2.2 below.

${ }^{8}$ See my article [16].

${ }^{9}$ D. Vanderveken's illocutionary logic introduces illocutionary denial for all types illocutionary acts; see $[11,74 ; 152-155]$. Here, I will deliberately confine my analysis solely to Denial as a veridictional operator opposing Assertion. One can thus consider my veridictional pragmatics as part of general illocutionary logic. This is why I will use its operators whenever possible. But I will make use of a system (equivalent to modal system $T$ ) that is less powerful than the one (S5) employed by illocutionary logic $(T \subset S 5)$.
} 
settling for simply considering the informative content of what he/she is saying. This is what Frege called das Fassen des Gedankens [2]. Consideration—borrowing the term used by Russell—is a cognitively fundamental operation since it conditions not only the reported speech procedures of natural language and artistic languages, but also the use of apagogical methods of hypothetical reasoning in the formal sciences [18]. Consideration, then, grants the speaker some distance from what he/she is saying, in such a way that the question of the speaker's veridictional commitment gets sidestepped.

\subsection{Estimation}

In the same way as assertion possesses an opposite, namely denial, simple consideration has an opposing operation which - for lack of a better term-I will call estimation, ${ }^{10}$ that is to say, the fact, for the speaker, of making a commitment about what he/she is saying, whether it be positively or negatively. Psychologically and cognitively, consideration and estimation are indeed two opposing attitudes that require a choice on the speaker's part.

\section{The opposition-based structure of veridictional acts}

The reader will have understood that veridictional acts are organized according to an opposition-based structure. Before describing this structure, let us first clearly separate the different levels of opposition. As early as 1904, Russell had already clearly distinguished the opposition between truth and falsity, underlain by the metalogical principle of bivalence; the opposition between the logical operations "affirmation" and "negation"; and the opposition between the psychological attitudes "belief" and "disbelief":

Given a proposition $p$, there is first its truth and its falsity.../...

Next there is the opposition of $p$ and not $-p . . . .$.

Thirdly, there is the subjective opposition of yes and no, which is that of belief or disbelief: either $p$ or not- $p$ can be believed or disbelieved: whether true or false, this is the opposition that specifically characterizes judgment and is absent in assumption $[9,56]$.

That left only the opposition between the strictly pragmatic operations of assertion and denial, which involves combining the logical operators that bear on propositional content with the pragmatic operations that characterize the speaker's attitude toward the truth of his/her utterance. Say we have at our disposal two logical operators that bear on propositional content, Affirmation and Negation; we still have

${ }^{10}$ I use this term to refer to "expressing an opinion about". It is closely tied to judgment, but in natural language, its "expressive" dimension remains implicit. 
to introduce the four pragmatic operations that determine the veridictional acts discerned above: Assertion, Denial, Estimation, and Consideration. If we acknowledge that Assertion and Denial are Estimation attitudes that oppose simple Consideration, then we can depict the combination of the four pragmatic operators of veridicity using the following binary tree:

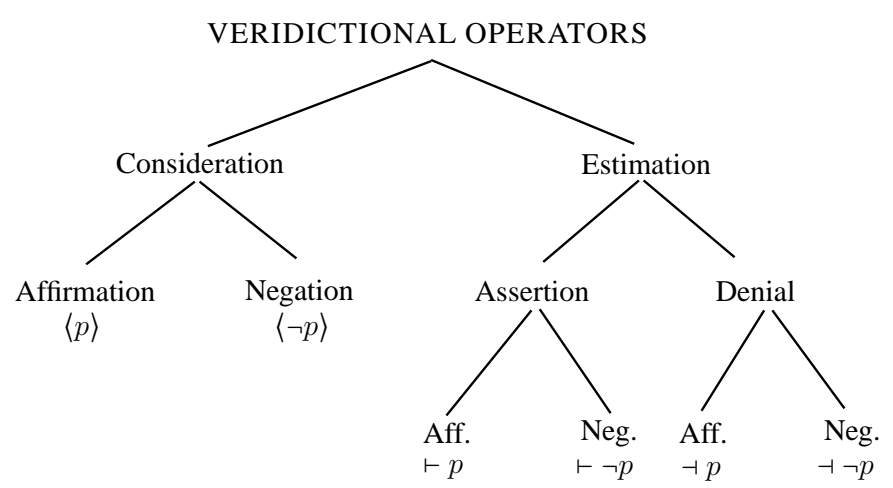

However, one must not be misled by this dichotomous presentation. Although truth-function oppositions abide by standard logic, governed by the principle of excluded middle, the same does not hold true at the pragmatic level: Assertion is opposed not only to Denial, but also to the third position of simple Consideration, i.e., suspension of any decision. ${ }^{11}$ The pragmatics of veridicity thus presupposes greater flexibility than strict propositional negation in accounting for the speaker's veridictional attitudes toward the informative content of his/her utterance.

\subsection{Relations between Veridictional Operators}

If, for simplicity's sake, we use letters of the alphabet to stand for veridictional acts, veridictional pragmatics will include the following operators:

$$
\begin{aligned}
& \mathrm{A}=\text { Asserting } \\
& \mathrm{C}=\text { Considering } \\
& \mathrm{D}=\text { Denying } \\
& \mathrm{E}=\text { Estimating }
\end{aligned}
$$

\footnotetext{
11 Ockham had already made the distinction between judgment (assent or dissent) and simple apprehension, which he named neutral proposition: "Someone can apprehend a proposition and yet not give it one's assent or dissent, as is patent with neutral propositions", [8, I, prol. qu. 1, p. 16]. Recall also that in the traditional disputatio, three attitudes were possible: concedo, nego, dubito.
} 
Relations between these veridictional operators can be depicted by the following alternative hexagon:

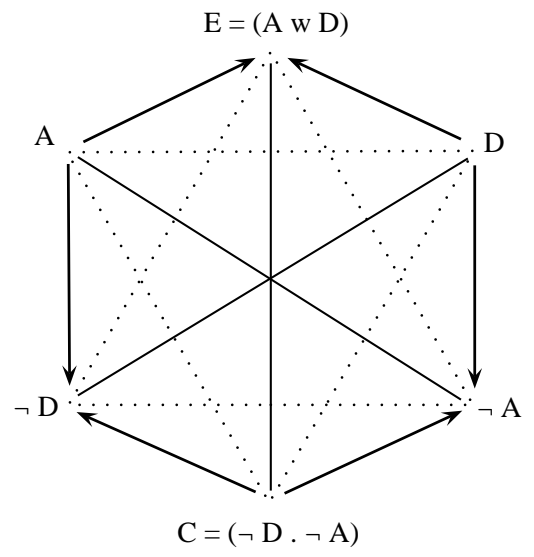

While relying on the theorems of my alternative axiomatic system, ${ }^{12}$ let me simply recall a few of the most significant logical relations:

1. The two primitive operators, Assertion and Denial, are opposites, that is to say, incompatible: $A \mathbf{P} \mid D \mathbf{P}(\mathrm{T} 2)$.

2. Non-contradiction is obeyed by suspensive negation of acts: $\neg(A \mathbf{P} \& \neg A \mathbf{P})(\mathrm{T} 29)$ and $\neg(D \mathbf{P} \& \neg D \mathbf{P})(\mathrm{T} 30)$, but also by exclusive negation: $\neg(A \mathbf{P} \& D \mathbf{P})(\mathrm{T} 3)$.

3. By contrast, the excluded middle no longer holds for $A$ and $D$, because it is quite possible to not choose between Asserting and Denying by adopting the neutral position, which is Consideration (T35). ${ }^{13}$

4. Double negation no longer holds for these same acts: not Denying $\mathbf{P}$ is not equivalent to Asserting $\mathbf{P}$. It is indeed always possible to adopt the neutral position of Consideration, and thus: $\neg A \mathbf{P}$. By subalternation, we get $A \mathbf{P} \triangleright \neg D \mathbf{P}$ (AX), but not its converse, thus: $\neg(A \mathbf{P} \approx \neg D \mathbf{P}) .{ }^{14}$ And likewise, by subalternation, we get $D \mathbf{P} \triangleright \neg A \mathbf{P}(\mathrm{T} 1)$, but not its converse, thus: $\neg(D \mathbf{P} \approx \neg A \mathbf{P})$.

The law of double negation does apply however to suspensive negation, denoted $\neg$. For example, we have: $\neg \neg A \mathbf{P} \approx A \mathbf{P}(\mathrm{T} 38)$ and $\neg \neg D \mathbf{P} \approx D \mathbf{P}(\mathrm{T} 40) .{ }^{15}$

\footnotetext{
12 The reader will find my axiomatization of the relations between the veridictional operators in the Appendix of my [19].

${ }^{13}$ We get the excluded quarter: $(A \vee D \vee C)$.

$14 \square$ is the symbol for illocutionary commitment between two acts; see [11, Chap. IV, 81]: " $A_{1} \triangleright A_{2}$ iff it is not possible for the speaker to realize $A_{1}$ without being committed to $A_{2}$ ". This relation is reflexive, non-anti-symmetric, and transitive; see p. $141 . \approx$ is the symbol for congruence of two illocutionary acts; see [11, Chap. IV, 82]: "Two illocutionary acts are congruent iff each one commits the speaker to the other". This equivalence relation is definable: $A_{1} \approx A_{2}$ iff $A_{1} \triangleright A_{2}$ and $A_{2} \triangleright A_{1}$ (where $A$ is any illocutionary act).

${ }^{15}$ It does not hold for exclusive negation, which means we do not have $A \mathbf{P} \triangleright D D \mathbf{P}$.
} 
5. Bivalence is preserved insofar as all propositions are either true or false: $\delta: \mathbf{P} \Rightarrow\{T, F\}$. Hence, when one is making a decision about a given proposition, it is not possible to not decide the opposite about the proposition that has the opposite truth value. So we have $A p \triangleright D \sim p$ (ET6) and $D p \triangleright A \sim p$ (ET7). This is a particular case where the veridictional operators bear on propositions that are mutually exclusive: $\mathbf{R} \mid \mathbf{S}$ (see the exclusivity theorems of our axiomatic system, ET1 to ET11).

\subsection{Syntactic Presentation}

Without formalizing the rules for building the formulas of the veridictional language, note simply that every formula is of the type: $F(£)$, where $£$ denotes the set of well-formed formulas of standard logical calculus $\{P, Q, R, S, \ldots\}$ built from the atomic propositions $p, q$, etc. by means of the standard connectors $\{\sim, \circ, \vee, \rightarrow$ , |, etc. $\}$, and where $F$ belongs to the set of all formulas built from the veridictional operators $\mathbb{V}=\{A, C, D, E\}$ and the set of all connectives bearing on illocutionary acts $\{\neg, \&, w, \mid, \triangleright, \approx\}$.

We can present our veridictional pragmatics as a particular interpretation, a model, of our bipolar axiomatic system ${ }^{16}$ of veridicity. Let me recall and comment upon its basic elements:

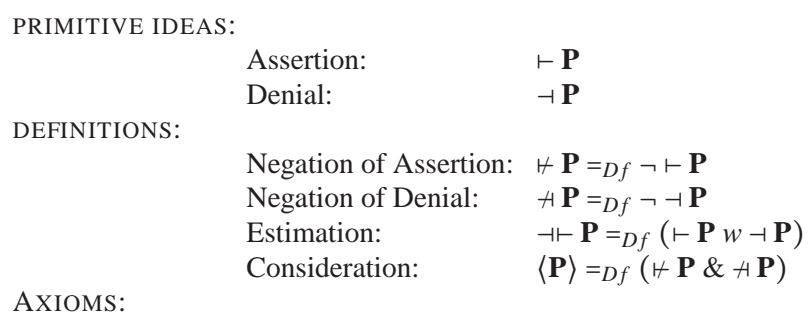

Axiom of Assertability: $A X_{1}: \vdash \mathbf{P} \triangleright \mathbf{P}$

The kind of assertion in question here is not logical assertion, but rather pragmatic assertion per se. What is at stake is not the validity of $\mathbf{P}$, but its veridicity. ${ }^{17}$ This axiom of assertability merely states that in asserting $\mathbf{P}$, the speaker commits to

\footnotetext{
16 This axiomatic system includes axioms for proving theorems and counter-axioms for proving counter-theorems. Regarding this bipolarity, see [20].

17 Of course, pragmatic assertion is the illocutionary act of a given speaker, which does not imply the truth, and all the less so, the validity of the proposition in question. It is not to be confused with logical assertion (demonstration) as defined by Russell and Frege, nor with what can be regarded as established, i.e., proven. This latter interpretation is the one that Jean de la Harpe adopted in [7, 26-31].
} 
the truth of $\mathbf{P}$. This in no way means that $\mathbf{P}$ is true, but that $\mathbf{P}$ is held to be true in the discursive world proposed by the speaker. ${ }^{18}$

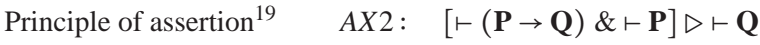

$$
\begin{aligned}
& \text { COUNTER-AXIOM: } \\
& \text { Counter-axiom of negation: } C A X 1 \quad \dashv(\neg A P \rightarrow \neg P)
\end{aligned}
$$

This axiomatic system ${ }^{20}$ allows one to prove all of the component relations of the alternative hexagon, as well as all relations that are excluded. For some pragmatically significant examples, simply consider the case of assertion iteration. With this axiomatic system, it is easy to prove left-to-right implication. One obtains General Theorem 11 from Axiom 1 by simple substitution:

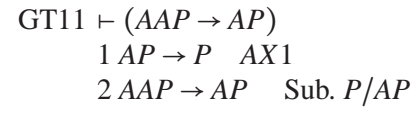

In contrast, to prove Counter-Theorem 1, which brings right-to-left implication into play, it is useful to first prove General Theorem 8, contraposition:

$$
\begin{array}{rlrl}
\mathrm{GT} 8 & \vdash(A P \rightarrow A Q) \equiv(\neg A Q \rightarrow \neg A P)] & \\
& (P \rightarrow Q) \equiv(\neg Q \rightarrow \neg P) & & \text { Tautology } \\
& (A P \rightarrow A Q) \equiv(\neg A Q \rightarrow \neg A P) & & \text { Sub. } P / A P ; Q / A Q .
\end{array}
$$

General Counter-Theorem 1 is then obtained as follows:

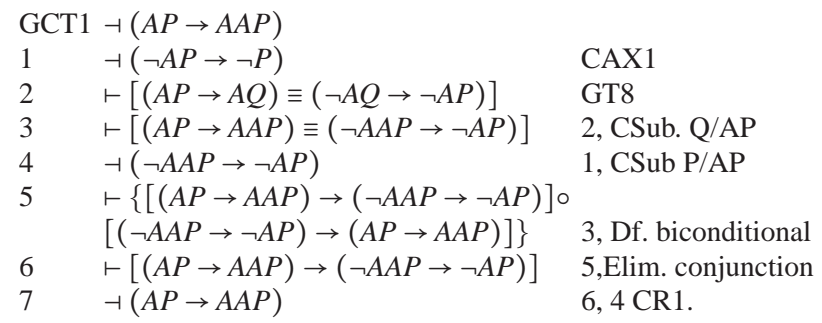

\footnotetext{
${ }^{18}$ This corresponds to what Karl Otto Apel called "pretension to truth" [1, 46].

${ }^{19}$ Here we find Russell's "Principle of assertion" (see our article "The Limits of a Logical Treatment of Assertion"). Unlike epistemic logic, which poses the question of omniscience $[K \mathbf{P} \&(\mathbf{P} \rightarrow$ $\mathbf{Q})] \rightarrow K \mathbf{Q}$, there is no risk of omnidiction here since we do not have to assert all of the consequences of our assertions: $\neg\{[\vdash \mathbf{P} \&(\mathbf{P} \rightarrow \mathbf{Q})] \triangleright \vdash \mathbf{Q}\}$.

${ }^{20}$ To simplify my presentation, I will not bring to bear the rules and counter-rules of transformation.
} 
This logically demonstrates that there is no equivalence between assertion and its iteration. We know that such an equivalence is only possible in a formal system as powerful as modal system $S 4$ and not in a system as weak as $T$ [5, 43-44].

Such a result is therefore not at all logically surprising or notable. However, it is of critical pragmatic interest in that it takes a stand on the interpretation of assertion iteration. From a strictly pragmatic point of view, it is wise indeed not to confuse or liken assertion and its iteration. Ap symbolizes the assertion of $p$ by a speaker. ${ }^{21}$ The speaker commits to the truth of the content of proposition $p$. This is the case, for example, when the speaker says: "It's raining." In contrast, $A A p$ denotes the operation whose rhetorical effect is to reinforce the strength of the initial assertion. In natural language, this is expressed by the fact that the speaker in the above example says something like: "I maintain that it's raining". Pragmatically, the two acts are manifestly different, the first being a simple assertion, true or false, the second, an act of a metadiscursive nature - precisely, an expositive - which, as such, cannot be untrue by virtue of the sheer fact that it was produced:

The sentence "It is the case that I maintain that it's raining" clearly has a different truth value than that of the sentence "It's raining" (the former can be true without the latter also being so). [1, 43]

If we acknowledge this conceptual distinction, ${ }^{22}$ we can understand why implication can hold true from left to right, for if one asserts a proposition, one cannot not assert it because the metadiscursive commitment is stronger than the simple assertion. In contrast, a simple assertion does not necessarily involve a stronger commitment, from which we can see that the fact of rejecting the right-to-left implication renders explicit an entire thematization and conceptualization of a pragmatic nature. ${ }^{23}$

\subsection{Semantic Presentation}

One can develop a semantics for interpreting and evaluating the propositions of this veridictional pragmatics. To do so, it is useful to complete these propositions by indicating the speaker who assumes the veridictional act. Accordingly, we use $\vdash_{a} \mathbf{P}$ to denote the fact that Speaker $a$ assumes the assertion of $\mathbf{P}$. The system is interpreted in the first person as the set of veridictional acts of Assertion, Denial, Estimation, and Consideration of a given speaker. We then evaluate the veridictional act on the discursive world ${ }^{24}$ that Speaker $a$ proposes by means of his/her various

\footnotetext{
${ }^{21}$ As we shall see in Section 2.3.1, a more sophisticated formalization that incorporates the speaker is possible; it gives us $A_{a} p$.

${ }^{22}$ Unlike Searle, who ignores the specificity of metadiscursives and unduly classifies "I assert that it's raining" among the assertives; see [10, 61].

${ }^{23}$ Daniel Vanderveken, who formalized Searle's theory, relies on a system equivalent to modal system $S 5$; see [12].

${ }^{24}$ Here, any illocutionary act is a proposal made by the speaker to the addressee, a proposal that must be negotiated to give rise to a jointly assumed "interact"; see [13, Chap. VIII], and [19, Chap. X, Section 4.1.1].
} 
veridictional acts, with world $W_{a}$ being accessible from initial world $W_{0}$. These acts can then be interpreted as follows:

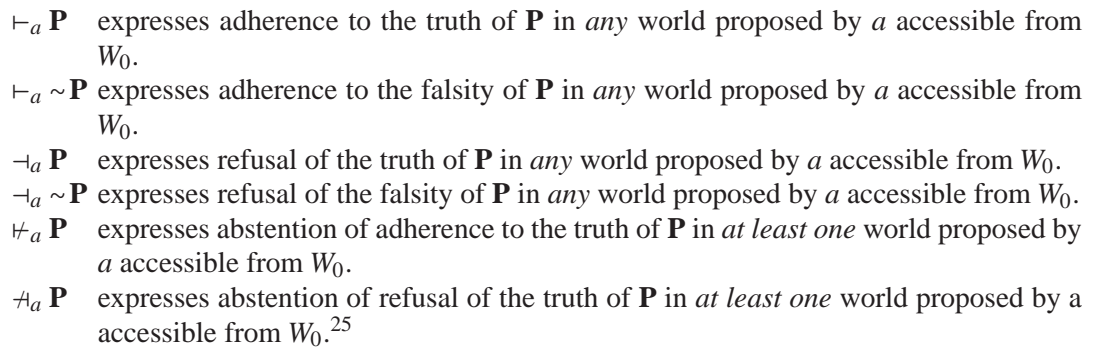

Using the semantic table method derived from Kripke, ${ }^{26}$ we can write down the veridictional acts in the representation of the discursive world proposed by Speaker $a$ while distinguishing what is asserted from what is not asserted, and within the notasserted, what is denied from what is not denied. By virtue of Laws ET6 and ET7 recalled above, whenever two incompatible expressions are involved, we will indicate what is asserted by the speaker and what commits him/her to the corresponding denial, and vice versa. Proofs will be by reductio ad absurdum: in initial world $W_{0}$, we will put the presumably false propositions in the right column, and the presumably true ones in the left column. First, we will write the formula to be evaluated at the top of the right column. Then we will analyze the formulas by assigning them to the right or left column according to the rules of the propositional operators, and we will process the elementary formulas obtained by writing down the concerned propositions in the world proposed by the speaker that is accessible from the initial world. An asserted proposition will be in the Assertion-of- $W_{a}$ box, a denied proposition will be in the Denial sub-box, and so on. When the initial formula is valid, we discover a contradiction in the world proposed by Speaker $a$.

Let us consider the formula: $\vdash_{a} p \triangleright \neg \neg_{a} p$

By reductio ad absurdum, we begin by writing the formula to be tested in $W_{0}$ 's False box (on the right). To falsify the commitment proposed, it suffices that its antecedent be true and its consequent, false. We then write the antecedent in the True box on the left. Presumably true, $\vdash_{a} p$ means that $p$ is to be written in the Assertion box (A) of Speaker $a$ 's proposed world. Applying Russell's Law leads us to write its opposite $\sim p$ in the opposite sub-box, Denial $(D)$. The last step is to write the consequent in the right box of $W_{0}$. Whereas $\neg \neg_{a} p$ must be false, $\neg_{a} p$, presumably true, moves to the right box. This allows us to write $p$ in the Denial sub-

\footnotetext{
${ }^{25}$ Formally, a Model is any triplet $\langle W, S, V\rangle$ in which $W$ is a proposed set of discursive worlds $W_{0}, W_{1}, \ldots ; R$ is the accessibility relation, which is reflexive $(x)(x R x)$ and thus serial $(x) E z(x R z)$; and $V$ is the function that attributes the values $\{1,0\} . V(A)$ thus reads as follows: For all $\mathbf{P}$ and $W_{i}, V\left(A \mathbf{P}, W_{i}\right)=1$ if for all $W_{j}$ such that $W_{i} R W_{j}, V\left(\mathbf{P}, W_{j}\right)=1$, else $V\left(A \mathbf{P}, W_{i}\right)=0$. Likewise, $V(I)$ reads: for all $\mathbf{P}$ and $W_{i}, V\left(I \mathbf{P}, W_{i}\right)=1$ if for at least one $W_{j}$ such that $W_{i} R W_{j}, V\left(\mathbf{P}, W_{j}\right)=1$, else $V\left(I \mathbf{P}, W_{i}\right)=0$.

${ }^{26}$ See [6]. The presentation used here is from Jean-Louis Gardies, [4, $58 \mathrm{sq}$.].
} 


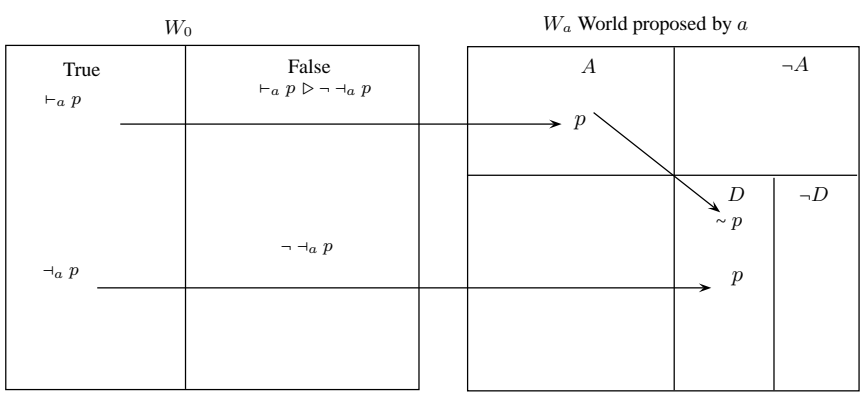

box of $W_{a}$. We then see that there is a contradiction, since the Denial box authorizes both $p$ and $\sim p$ in $W_{a}$. The initial formula is thus proven (it corresponds to axiom $A X$ of our alternative axiomatic system).

Similarly, let us consider the converse: $\neg \vdash_{a} p \triangleright \vdash_{a} p$

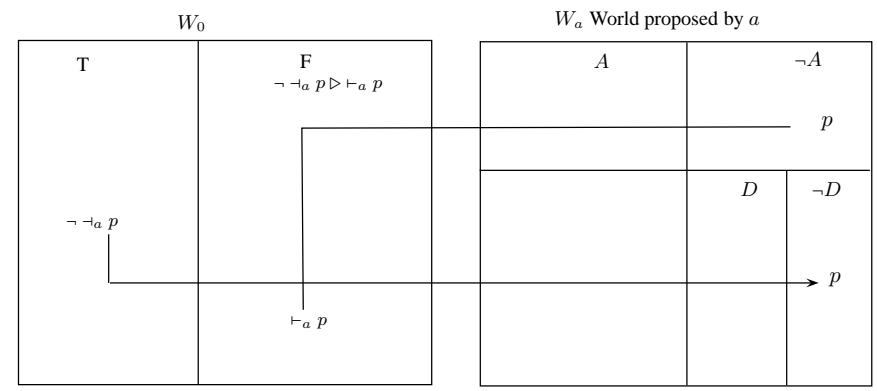

The presumably false formula is put in the right box of $W_{0}$. Then its antecedent is put on the left, which allows us to write $p$ in $W_{a}$ 's not-Denied sub-box. The next step is to put the consequent in $W_{0}$ 's right box, from which we can write $p$ in $W_{a}$ 's not-Asserted box. This time, there is no contradiction, $p$ is both not asserted and not denied. The formula is therefore invalid. ${ }^{27}$

Similarly, it is easy to show that $\vdash_{a} p \vee \dashv_{a} p$ is not valid:

To assume that the disjunction is false, one must assume that each of the disjuncts is false; so they are written in the left box of $W_{0}$. The falsity of $\dashv_{a} p$ causes us to write $p$ in the not-Asserted box of $W_{a}$; likewise, the falsity of $\vdash_{a} p$ requires that we write $p$ in the not-Denied sub-box of $W_{a}$. We can easily see that the initial formula is not contradictory and that there exists a third position between Assertion and Denial, namely Consideration, as a suspensive conjunction of the not-Asserted and the not-Denied.

27 The counter-position corresponds to the formula $\neg A \rightarrow E$, which is not included in our axiomatic system since it is equivalent to the inclusive disjunction: $A \vee E$. 


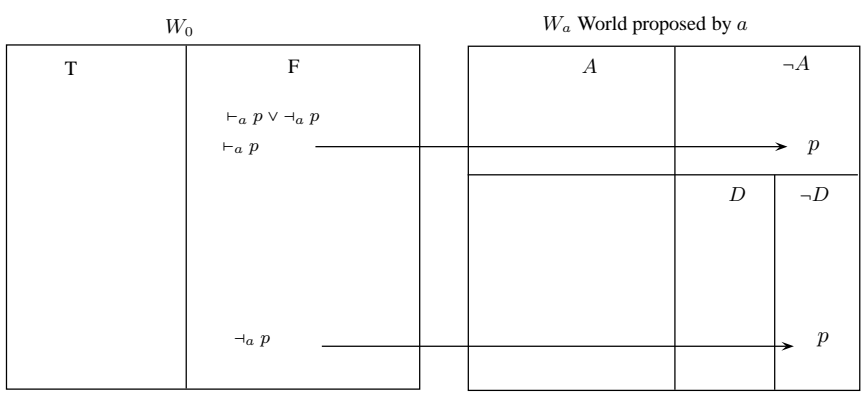

\subsubsection{Multi-Agent Extension}

One can extend the veridictional language to build a multi-agent, veridictional pragmatics. It allows us to express the combination of veridictional actions taken by different agents about a given proposition such as $\mathbb{V}_{a} \mathbb{V}_{b} \mathbf{P}$, where, for example, $A_{a} D_{b} p$ stands for "Agent $a$ asserts that Agent $b$ denies $p$ ". ${ }^{28}$ Now we can evaluate formulas of this type by making the world the second agent proposed, $W_{a b}$, subordinate to the one the first agent proposed, $W_{a}$. The subordinate world will not represent what the second agent said, but what the first agent said that the second agent, $b$, said.

The formula to be evaluated here is: $D_{a} A_{b} p \triangleright \neg A_{a} D_{b} \sim p$.

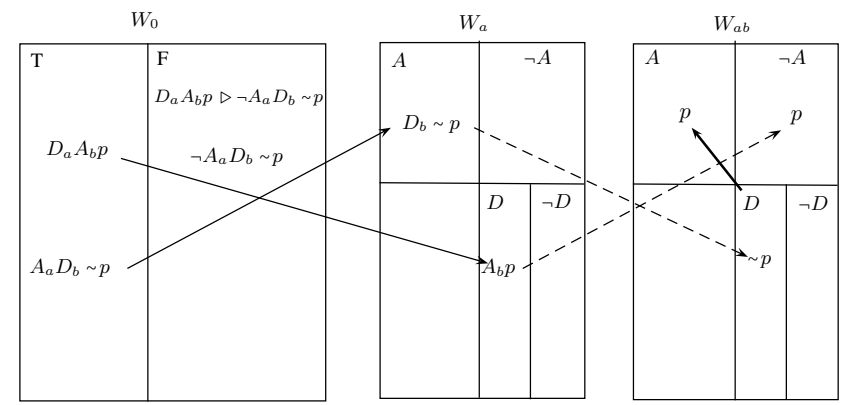

This formula is written in the part right of $W_{0}$. The antecedent $D_{a} A_{b} p$ is then moved to the left part. This leads us to write $A_{b} p$ in sub-box D of $W_{a}$ and thus, $p$ in the $\neg A$ box of $W_{a b}$. This leaves the consequent $\neg A_{a} D_{b} \sim P$, which we put in the right part of $W_{0}$. Given that it is preceded by a negation, its affirmative converse moves to the left. So $A_{a} D_{b} \sim p$ leads us to write $D_{b} \sim p$ in box $A$ of $W_{a}$ and thus $\sim p$ in sub-box $\mathrm{D}$ of $W_{a b}$. Now by virtue of Russell's Law, $p$ must be written in box A of the same world. We can see a contradiction in this world since $p$ cannot be both asserted and not asserted. Because negation of the formula is not possible, this formula is valid.

Likewise, we can symbolize the conjunction of actions of agents about different propositions, such as $\mathbb{V}_{a} \mathbf{P} \& \mathbb{V}_{b} \mathbf{Q}$. This construction authorizes the formalization of

${ }^{28}$ For greater clarity, I again use letters of the alphabet to symbolize veridictional acts. 
the veridictional Agreement of two (or more) agents about the same proposition. Here, we have:

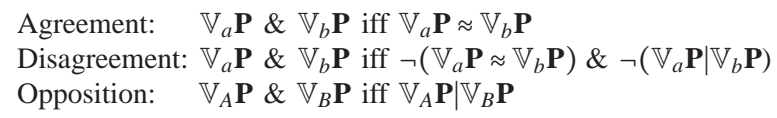

There will be agreement if the two agents assert the same proposition (or two propositions that they acknowledge to be equivalent), for example, $\vdash_{a} \mathbf{P} \& \vdash_{b} \mathbf{P}$, and opposition if they take incompatible stances, such as: $\vdash_{a} \mathbf{P} \& \dashv_{b} \mathbf{P}$.

This type of operator provides the link between the present pragmatic dimension of veridicity and the strictly dialogical one developed in our Dialogical Logic of Veridicity, aimed at handling relations of agreement, disagreement, and opposition between agents about a given proposition.

\section{Doxastic correlates of veridictional acts}

Like any formal system, an axiomatic system can receive several different models. Accordingly, our pragmatic theorization of veridictional acts can serve as a model of our bipolar axiomatic system. But other models are conceivable. Our axiomatic system provides a formal structure that holds not only for veridictional speech acts, but also for states of mind, the belief attitudes associated with them. This gives us the following hexagon, which expresses the logical relations between the doxastic correlates $^{29}$ of veridictional acts:

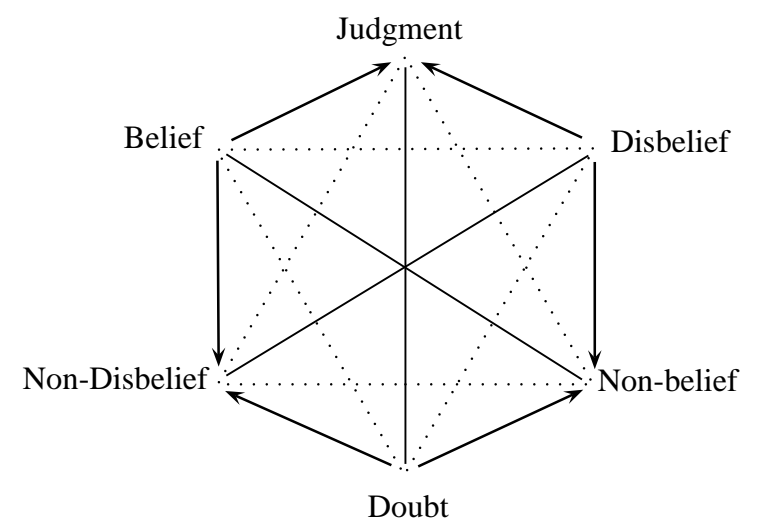

${ }^{29}$ The strictly epistemic dimension can only intervene in the framework of our Dialogical Logic of Veridicity, [21] which accounts for agreement (or disagreement) about the truth in question. Knowledge is necessarily dialogically mutualized. 
A judgment, which is a veridictional commitment expressed by an Assertion or a Denial, rests on an attitude of either Belief or Disbelief and corresponds to the act of Estimation. Doubt, as a mental state, corresponds to the neutral, suspensive position of simple Consideration, i.e., both non-belief and non-disbelief.

The theory of veridictional acts and the theory of mental states thus turn out to be two isomorphic models of one and the same axiomatic architecture. Just as it did for speech acts, this formal architecture enables one to clarify and systematize the theory of mental acts. To illustrate with a single example, it establishes logically that one should not—contrary to what is all too often done-confuse disbelief, which is a question of denial, with non-belief, which depends on non-assertion. ${ }^{30}$

\section{Conclusion}

The analysis I have just proposed is first and foremost a logical analysis, in that it draws from the age-old "square of opposition" to precisely define the relations between the various possible veridictional acts: Assertion, Non-Assertion, Denial, Non-Denial, Estimation, and Consideration. Although I have chosen to propose an alternative to the hexagon of opposition in order to account for the incompatibility between Assertion and Denial, the laws of standard propositional calculus are assumptions therein. Accordingly, the theorems of that calculus as well as those of the proposed axiomatic system can be asserted by applying rule R1 of the alternative axiomatic system. ${ }^{31}$

The logical dimension is thus patent. But it must not conceal the strictly pragmatic dimension. This means recognizing the difference-which I have never stopped stressing - between logical assertion as a formal, anonymous deduction procedure, and pragmatic assertion as an act of a particular speaker. In other words, one must acknowledge the difference between logical, formal, anonymous truth, and veridicity as an act of a speaker who commits personally to the truth of what he/she is saying. Hence, the axiom of veridicity says nothing about the truth of what is said by the speaker.

In any case, this pragmatics of veridicity does not claim to answer the ancient question of the truth, which requires a praxiological type of approach, one that relates the saying to the doing, the words of speakers to the worlds in which those speakers act. ${ }^{32}$

Moreover, the question of veridicity itself is not for as much answered by this logico-pragmatic analysis. As it is described above, my pragmatic logic of veridicity only deals with the acts of a single speaker or with the compared attitudes of two speakers (agreement, opposition, disagreement). As such, the analysis remains

\footnotetext{
${ }^{30}$ On this crucial distinction, see [19, Chap. I, Chap. VII].

${ }^{31}$ See $R 1: \vdash \mathbf{P} \Rightarrow \vdash A \mathbf{P}$, where $\vdash$ is the metalogical symbol for deduction and $A$, that of the act of assertion.

32 This praxiological dimension is analyzed in [19, Chap. XI].
} 
abstract, for it does not address the fundamentally dialogical dimension of discourse. Speech acts are not definable monologically. For example, assertion could never be reduced to the formal schema $A_{a} p$, but only to $A_{a b} p$ insofar as this formula alone expresses the speaker's commitment to the truth of $p$ relative to an addressee $b{ }^{33}$ What's more, these acts only become meaningful in the context of a dialogue wherein they are the outcome of a negotiation process between the interlocutors aimed at their being assumed as interacts. ${ }^{34}$ Last but not least, these interacts do not take on a dialogical function unless they serve as moves in the "language game" in which the argumentative exchange that ensures or does not ensure veridictional agreement is being played. ${ }^{35}$

The purpose of the above analysis, then, was solely to rigorously, i.e., logically, define the possible relations between the veridictional acts that characterize a speaker's pragmatic attitude toward what he/she acknowledges, refuses, or simply considers.

In fine, one can also wonder from a zetetic standpoint whether this formalizationleading to a pragmatics of veridictional acts extended to their doxastic correlatesmight apply, cum grano salis, not to "constative" acts this time, which bring into play the information transmitted between the speaker and the addressee, but strictly to acts of the "performative" type, which introduce purely actional rapports between a speaker and an addressee facing a to-be-solved problem, in a particular situation. I will leave this question unanswered for now.

\section{References}

1. Karl Otto Apel. Le Logos propre au langage humain. Éditions de L’Éclat, 1994. translated by M. Charrière \& J.-P. Cometti.

2. G. Frege. Écrits logiques et philosophiques, chapter Recherches logiques, I - La pensée, II La négation, pages 170-213. Seuil, Paris, 1971.

3. Sigmund Freud. Résultats, idées, problèmes, chapter La négation, pages 135-139. Presses Universitaires de France, Paris, 1985. Original text in: Imago, 11(3), 1925, 217-221.

4. Jean-Louis Gardies. Essai sur la logique des modalités. Presses Universitaires de France, Paris, 1979.

5. G. E. Hugues and M. J. Cresswell. An Introduction to Modal Logic. Methuen \& Co, 1968.

6. Saul Kripke. Semantical Analysis of Modal Logic I. Normal Propositional Calculi. Zeitschrift für mathematische Logik und Grundlagen der Mathematik, 9:67-96, 1963.

7. Jean de La Harpe. La Logique de l'assertion pure. Presses Universitaires de France, Paris, 1950.

8. Guillelmi De Ockham. Scriptum in librum primum Sententiarum, Ordinatio, Prologus et distinctio prima. St Bonaventure, New York, 1979.

9. Bertrand Russell. Meinong's Theory of Complexes and Assumptions. In D. Lackey, editor, Essays in Analysis. Allen \& Unwin, London, 1973.

\footnotetext{
${ }^{33}$ See [13, Chap. IV].

${ }^{34}$ See [13, Chap. VIII] and [19, Chap. X, Section 4.1.1.1].

${ }^{35}$ By themselves, assertions are pure abstractions. An assertion assumes a particular function in a dialogue only as a response, a reply, an inquiry, a questioning, etc. See [19, Chap. IX].
} 
10. J.R. Searle. Sens et expression, Études de théorie des actes du langage. Le sens commun. Éditions de Minuit, Paris, 1982. Traduit de l'anglais (États-Unis) et préfacé par Joëlle Proust.

11. J.R. Searle and D. Vanderveken. Foundations of Illocutionary Logic. Cambridge University Press, Cambridge, 1985.

12. D. Vanderveken. Meaning and Speech Acts - vol. 1, Principles of Language Use, vol. 2, Formal Semantics of Success and Satisfaction. Cambridge University Press, Cambridge, 1990.

13. D. Vernant. Du discours à l'action. Presses Universitaires de France, Paris, 1997.

14. D. Vernant. The Limits of a Logical Treatment of Assertion. In D. Vanderveken, editor, Logic, Thought and Action. Springer, 2005.

15. D. Vernant. Pour une analyse pragmatique de l'acte de citer : les métadiscursifs. In A. Wall and M.-D. Popelard, editors, Citer l'autre, pages 179-194. Presses de la Sorbonne Nouvelle, Paris, 2005b.

16. D. Vernant. La genèse logique de la dénégation. In R. Pouivet and M. Rebuschi, editors, Philosophie et logique en Pologne 1918-1939, Analyse et Philosophie, pages 151-178. Vrin, Paris, 2006.

17. D. Vernant. Définition stratifiée de la véridicité. In P. Joray and D. Miéville, editors, Définition, Rôles et fonctions en logique et en mathématiques, pages 205-237. Université de Neuchâtel, Neuchâtel, 2008.

18. D. Vernant. L'argumentation par l'absurde : l'opération pragmatique de considération. In $L a$ Logique et les normes, Hommage à J.-L. Gardies, number 25 in Recherches sur la philosophie et la langage, pages 73-90. Vrin, Paris, 2008b.

19. D. Vernant. Discours et Vérité. Vrin, Paris, 2009.

20. D. Vernant. Sur la bipolarité des concepts, des théories et des axiomatiques. In P.-E. Bour, M. Rebuschi, and L. Rollet, editors, Construction, Festschrift für Gerhard Heinzmann, Tributes, pages 667-681. College Publications, London, 2010.

21. D. Vernant. The Dialogical Logic of Veridicity. In A. Trognon, M. Batt, J. Caelen, and D. Vernant, editors, Logical Properties of Dialogues. Presses Universitaires de Nancy, 2010. 